\title{
Cerebral Metastases as First Clinical Manifestation of Ovarian/Fallopian Tube Carcinoma
}

\author{
Atsushi Imai*, Satoshi Ichigo, Hiroshi Takagi, Ichiro Kawabata and Kazutoshi Matsunami \\ Department of Obstetrics and Gynecology, Japan
}

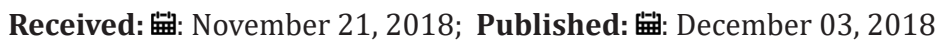

*Corresponding author: Atsushi Imai, Matsunami General Hospital, 185-1 Dendai, Kasamatsu, Gifu 501-6062, Japan

\begin{abstract}
Cerebral metastases from ovarian/fallopian tube carcinoma, rare and highly dismal events, develop usually in patients with prolonged survival. There are only several reports on cancers in which brain involvements are present before or at the time of diagnosis of primary ovarian/fallopian tube carcinoma. Therefore we attempted to systemically review available evidence on brain metastasis as a first manifestation of ovarian/fallopian tube carcinomas. Consideration of the brain as a potential site of metastasis even early in the primary lesion may lead us to consider the occult ovarian/fallopian tube carcinoma in females affected by brain involvements.
\end{abstract}

Keywords: Ovarian Carcinoma; Fallopian Tube Carcinoma; Brain Metastasis; First Clinical Manifestation; Occult Primary Tumor

\section{Introduction}

Recent knowledge on histopathology and genetics have induced a paradigm shift that peritoneal, ovarian and fallopian tube carcinomas are considered as a spectrum of disease originating from the Müllerian duct remnant [1,2]. Intraperitoneal dissemination is the most commonly encountered pattern and initial distant metastasis beyond the liver or lung, including brain, is very rare [3]. Central nervous system involvement occurs as a late manifestation of the disease developing after the initial diagnosis of primary tumor; less than $5 \%$ are of the carcinoma [4-6]. The multimodal treatment with a combination of surgery, chemotherapy and radiotherapy may improve survival but also increase the incidence of brain metastases [4-6]. Diagnosis of brain metastases which precede the diagnosis of ovarian/fallopian tube origin rarely occurs. In such cases, the carcinoma may be remarkable for the small size of the occult primary tumor and the early metastatic spread to the brain, which is ultimately responsible for the patient's presenting symptoms. Considering the brain as a potential site of metastasis even early in the primary lesion may give a new insight to identify the factors, both host and tumor based, that could make the brain prone to metastasis so early in the disease process.

\section{Literature Review}

In a literature review we found 5 single case reports in which brain metastases were present on initial presentation of ovarian/ fallopian tube carcinomas before or at the time of diagnosis of primary cancer (Table 1). The poorly differentiated adenocarcinoma accounts for $40 \%$, and the characterized as endometrioid adenocarcinoma, clear cell carcinoma and serous adenocarcinoma only I one case. Metastases prefer the parenchyma rather than the leptomeninges in all cases as previously reported [7,8], usually as a single lesion [9-11], but also multiple in 2 cases [7,12].

Table 1: Brain metastases as first clinical manifestation of fallopian and ovarian carcinoma.

\begin{tabular}{|c|c|c|c|}
\hline Authors, Year & Age (Years) & Histology & Local Findings in Primary Site \\
\hline Matsunami et al [10] & 36 & $\begin{array}{c}\text { Endometrioid Adenocarcinoma, } \\
\text { Ovary }\end{array}$ & Corresponding to stage IA \\
\hline Raff et al. [11] & 63 & $\begin{array}{c}\text { Poorly Differentiated } \\
\text { Adenocarcinoma, Fallopian Tube }\end{array}$ & $\begin{array}{c}\text { Corresponding to stage IC, (positive } \\
\text { pelvic washing cytologic examination) }\end{array}$ \\
\hline Al Barbarawi et al. [12] & 41 & Clear Cell Carcinoma, Ovary & Corresponding to stage IA \\
\hline
\end{tabular}




\begin{tabular}{|c|c|c|c|c|}
\hline Bakar and Tekkök [7] & 56 & $\begin{array}{c}\text { Poorly Differentiated } \\
\text { Adenocarcinoma, Ovary }\end{array}$ & $\begin{array}{c}\text { Corresponding to stage IA, (negative } \\
\text { pelvic washing cytologic examination, but } \\
\text { positive paraaortic lymph node) }\end{array}$ & Multiple \\
\hline Alafaci et al. [9] & not described & $\begin{array}{c}\text { Papillary Serous Adenocarcinoma, } \\
\text { Ovary }\end{array}$ & Corresponding to stage I, not operated & Single \\
\hline
\end{tabular}

\section{Comments}

Upon analyzing 12 previous articles on the clinical course of brain involvement in patients without a known primary tumor [13-24], $60-70 \%$ of total patients eventually had a primary cancer identified. The most commonly identified source was lung cancer. Other frequently discovered primary tumors include gastrointestinal tumors and melanoma, in approximately 10 to $15 \%$ of cases. Primary origin cancers remained unidentified in approximately $30 \%$ of all cases; ovarian/fallopian tube carcinoma was not mentioned in these articles. Brain metastasis may occur via the unique cerebrospinal venous system named as Batson's plexus. This system consists of veins, sinuses and venous plexuses [25], communicating with the veins around the spinal column, the segmental veins of thoracoabdominal wall, the plexuses and the azygous system of veins of pelvic organ. The main characteristics of the Batson plexus is lack of venous valves. This lack of venous valves causes bidirectional blood flow, and it may play as a route for rostral metastatic spread of tumor, infection or emboli from pelvic organs $[26,27]$.

The lack of spread into the pelvic, intraabdominal or thoracic organs except for local lymph node metastasis suggests that the brain metastases probably occurred by tumor cell dissemination hematogenous through the Batson plexus. Ovarian/fallopian tube carcinoma is common but metastasizes rarely to the brain. The brain involvement is traditionally considered as a late manifestation of the diseases and generally occur in patients with prolonged survival. The metastatic brain involvement of brain as early presentation of ovarian/fallopian tube carcinoma is extremely unusual, but we suggest the importance of considering the brain as a potential site of metastasis, even early in the disease course of ovarian/fallopian tube carcinoma. There is some evidence that patients with only solitary brain metastases may have an improved prognosis. The possibility of the occult ovarian/fallopian tube carcinoma should be always considered in females with brain involvements.

\section{References}

1. Kurman R, Shih I (2016) The dualistic model of ovarian carcinogenesis: revisited, revised, and expanded. Am J Pathol 186(4): 733-747.

2. Cobb L, Gaillard S, Wang Y, Shih I, Secord A (2015) Adenocarcinoma of Mullerian origin: review of pathogenesis, molecular biology, and emerging treatment paradigms. Gynecol Oncol Res Pract 2: 1.

3. Cormio G, Rossi C, Cazzolla A, Resta L, Loverro G, et al. (2003) Distant metastases in ovarian carcinoma. Int J Gynecol Cancer 13(2): 125-129.

4. Hidaka T, Nakamura T, Shima T, Sumiya S, Saito S (2004) Cerebral metastasis from a primary adenocarcinoma of the fallopian tube. Gynecol Oncol 95(1): 260-263.

5. Pectasides D, Pectasides M, Economopoulos T (2006) Brain metastases from epithelial ovarian cancer: a review of the literature. Oncologist 11(3): 252-260.
6. Kolomainen D, Larkin J, Badran M, A'Hern R, King D, et al. (2002) Epithelial ovarian cancer metastasizing to the brain: a late manifestation of the disease with an increasing incidence. J Clin Oncol 20(4): 982-986.

7. Bakar B, Tekkök I (2008) Primary undifferentiated ovarian carcinoma diagnosed by its metastasis to brain: an unusual case report. Turk Neurosurg 18(4): 431-435.

8. Ohta H, Koyama R, Nagai T, Hirayama Y, Saito S, et al. (2001) Meningeal carcinomatosis from an ovarian primary with complete response to adjuvant chemotherapy after cranial irradiation. Int J Clin Oncol 6(3): 157-162.

9. Alafaci C, Caffo M, Caruso G, Barresi V, Cutugno M, et al. (2011) Brain metastases as first clinical manifestation of ovarian carcinoma. Clin Neuropathol 30(4): 203-205.

10. Matsunami K, Imai A, Tamaya T, Takagi H, Noda K (1999) Brain metastasis as first manifestation of ovarian cancer. Eur J Obstet Gynecol Reprod Biol 82(1): 81-83.

11. Raff JP, Anderson P, Sands C, Makower D (2002) Fallopian tube carcinoma presenting with a brain metastasis. Gynecol Oncol 85(2): 372-375.

12. Al Barbarawi M, Smith S, Qudsieh S, Sekhon L (2005) Multiple cerebral and leptomeningeal metastases from ovarian carcinoma: unusual early presentation. J Clin Neurosci 12(6): 697-699.

13. Le Chevalier T, Smith F, Caille P, Constans J, Rouesse J (1985) Sites of primary malignancies in patients presenting with cerebral metastases $\mathrm{A}$ review of 120 cases. Cancer 56(4): 880-882.

14. Eapen L, Vachet M, Catton G, Danjoux C, McDermot R, et al. (1988) Brain metastases with an unknown primary: a clinical perspective. J Neurooncol 6(1): 31-35.

15. Merchut M (1989) Brain metastases from an undiagnosed systemic neoplasm. Arch Intern Med 149(5): 1076-1080.

16. Debevec M (1990) Management of patients with brain metastases of unknown origin. Neoplasma 37(5): 601-606.

17. Chee C (1990) Brain metastases of unknown origin. Singapore Med J 31: 48-50.

18. Salvati M, Cervoni L, Raco A (1995) Single brain metastases from unknown primary malignancies in CT-era. J Neurooncol 23(1): 75-80.

19. Van de Pol M, Van Aalst V, Wilmink J, Twijnstra A (1996) Brain metastases from unknown primary tumour: which diagnostic procedures are indicated? J Neurol Neurosurg Psychiatry 61(3): 321-323.

20. Nguyen L, Maor M, Oswald M (1998) Brain metastases as the only manifestation of an undetected primary tumor. Cancer 83(10): 21812184.

21. Maesawa S, Kondziolka D, Thompson T, Flickinger J, Dade L (2000) Brain metastases in patients with no known primary tumor. Cancer 89(5): 1095-1101.

22. Giordana M, Cordera S, Boghi A (2000) Cerebral metastases as first symptom of cancer: a clinico-pathologic study. J Neurooncol 50(3): 265273.

23. Rudà R, Borgognone M, Benech F, Vasario E, Soffietti R (2001) Brain metastases from unknown primary tumor: a prospective study. J Neurol 248(5): 394-398.

24. Thomas A, Rock J, Johnson C, Weiss L, Jacobsen G, et al. (2000) Survival of patients with synchronous brain metastases: an epidemiological study in southeastern Michigan. J Neurosurg 93(6): 927-931. 
25. Batson $O$ (1940) The function of the vertebral veins and their role in the spread of metastases. Ann Surg 112(1): 138-149.

26. Tobinick E, Vega C (2006) The cerebrospinal venous system: anatomy, physiology, and clinical implications. MedGenMed 8(1): 53.

\section{ISSN: 2574-1241}

DOI: 10.26717/BJSTR.2018.11.002134

Atsushi Imai. Biomed J Sci \& Tech Res

(c) (P) This work is licensed under Creative

Submission Link: https://biomedres.us/submit-manuscript.php
27. Pearce J (2006) The craniospinal venous system. Eur Neurol 56(2): 136138.

$\begin{array}{ll}\text { BIOMEDICAL } & \text { Assets of Publishing with us } \\ \text { RESEARCHES } & \text { - Global archiving of articles } \\ \text { - Immediate, unrestricted online access } & \text { - Rigorous Peer Review Process } \\ & \text { - Authors Retain Copyrights }\end{array}$

